\title{
Abstinence in treated and untreated opiate abusers: a study of a prison sample
}

\author{
Paul O’Mahony, MA, MSc, PhD, Research psychologist, Department of Justice.
}

\begin{abstract}
Twenty-four out of a systematic sample of 95 Mountjoy prisoners were found to have been daily users of opiates. Half of the opiate using prisoners had been abstinent before entering prison for an average of 17.5 months. However, 11 of the total 24 subjects and seven of the 12 abstinent prisoners had not been exposed to any treatment other than detoxification.
\end{abstract}

Key Words: Narcotic dependence; heroin dependence; prognosis; prisons.

\section{Introduction}

In recent years, there has been a growing awareness of the need for long-term follow-up in the evaluation of treatments for all forms of addiction..$^{1-3}$ Gossop et $a l^{4}$, for example, have stated that there can be few questions more central to this area than what happens to drug-dependent patients after they leave a treatment programme, but they conclude that "it is unfortunate that this apparently simple question has received so little research attention". However, in the specific area of the treatment of alcoholism, several major longitudinal studies have been recently published, ${ }^{5-8}$ and one author, Vaillant, ${ }^{9}$ has managed to examine the history of treated alcoholics for periods of up to 40 years after treatment. These studies, because they take a sufficiently long-term perspective, have brought to light important aspects of the natural history of alcoholism, for example, by documenting the instability of drinking patterns and the low probability of complete abstinence over the long term.

The concept that addictive behaviours have a natural history, i.e. are characterised by specific patterns of developmental change, of itself suggests the need for caution in the interpretation of short-term treatment outcomes with addicts. For instance, Gossop ${ }^{2}$ argues that the widespread belief that treatment of opiate dependence is largely ineffective, has been powerfully reinforced by the reliance on the short-term occurrence or avoidance of relapse as the chief measure of failure or success. Gossop reports figures from the Maudsley Relapse Study ${ }^{10}$, which showed that at least one third of opiate dependent patients, who had relapsed by six weeks after treatment, had nonetheless become stably abstinent at six months after treatment. He concludes that an initial lapse after treatment, although often taken as a measure of treatment failure, is not in fact a sign of inevitable readdiction and that, therefore, many outcome studies fail to do justice to the positive effects of the treatments they evaluate. Nathan and Skinstead, ${ }^{3}$ on the other hand, point out that researchers are as likely to overestimate as under-estimate treatment effects by their failure to assess outcome over a sufficiently long follow-up period.

However, inadequate length of follow-up is not the only common failing of treatment evaluation studies. Equally serious is the frequent lack of a control group and the consequent failure to compare outcomes for treated and untreated addicts. Indeed, outcome studies with control groups and studies of the natural history of addictive behaviour have drawn attention to a relatively high rate of so-called spontaneous remission in most addictions. These studies have shown that there are often periods of stable abstinence which cannot be attributed to any specific formal treatment. ${ }^{9,11,12,13}$ Emrick $^{14}$ has concluded that many alcoholics "drink less or stop altogether with no or minimal treatment". Vaillant ${ }^{9}$ has gone so far as to suggest that "alcoholics recover not because we treat them but because they heal themselves". Orford ${ }^{12}$ 
has provided a comprehensive cost/benefit, approach/avoidance model of addictive behaviours of all kinds, which can account for the frequent occurrence of episodes of remission and prolonged abstinence in the absence of any treatment.

In this context, it can be seen that Gossop's question about what happens after treatment is not the only seriously neglected question. A thorough and valid evaluation of treatment interventions with addicts needs to examine outcomes over an adequate follow-up period but also needs to compare treatment results with the base-rate of remission and abstinence amongst similar untreated addicts. It is, therefore, necessary to collect information about the group of addicts who never receive treatment. Acknowledge of what happens to this group is essential to the full understanding and assessment of treatment intervention. After all, it is legitimate to attribute to treatment effects only those gains, in a given time period, which are over and above the number of remissions that can normally be expected in the absence of treatment.

In the absence of reliable Irish data in this area, this paper provides information on the exposure to treatment and the pre-incarceration abstinence status of a small group of imprisoned, male, opiate users. The sample studied is clearly not a representative sample of the population of Irish male opiate users. However, it is the author's assumption that a considerable proportion of Irish male, opiate users find themselves in prison at some point, and that, ipso facto, this sample's experience is reflective of the experience of a considerable proportion of the Irish male opiate-using population. The purpose here is to sketch in broad outline the dimensions of the problem, in other words to provide a first estimate for (1) the proportion of well-established opiate users who have never undergone treatment, and (2) the abstinence status of this untreated group.

\section{Subjects and method}

The 24 subjects of this study were selected, by a screening procedure, from a one-fifth systematic sample of the population of Mountjoy Prison, made in June 1986 as part of a larger survey. The systematic sample totalled 110 prisoners from an overall prison population of 550. The prisoners were listed according to the cell or the bed, in the case of multiple cells, which they occupied. A prisoner was selected at random from the first five listed and from then every fifth prisoner was selected from the list. Involvement in the research was entirely voluntary and 15 prisoners refused to cooperate. This was a non-response rate of $13.6 \%$, which can be considered reasonable, particularly in a prison environment.

The subjects were screened, during an extensive, explicitly confidential interview on other topics, by means of a short series of questions relating to their experience of drug use. Those prisoners who reported having been daily users of opiates for a period of at least a month were selected for inclusion in this study. Their inclusion entailed a separate, detailed interview on the topic of drug use. All 24 prisoners who met the inclusion criteria agreed to participate in the second interview on drug use.

The data on which this study is based are derived from self-reports and are not supported by any additional independent line of evidence. This is clearly a limitation. However, there are no grounds for assuming that the subjects either were not fully frank or set out to deceive the researcher. Indeed, earlier research undertaken with imprisoned heroin abusers ${ }^{15}$ indicated that they were significantly less likely than a control group of civil servants to either consciously or unconsciously present a falsely positive picture of themselves on a self-report scale.

The inclusion criteria are stict and ensure a narrowly defined study group who have all experienced serious drug misuse. Of the 24 subjects, 23 had been daily intravenous users of opiates, usually heroin and Diconal (Dipipanone), and one had smoked heroin daily. On average, they had begun using opiates slightly more than seven years before the time of the interview and at their peak of use had taken about .75 grammes daily. 
Given the focus of this inquiry on exposure to treatment, it is clearly essential to select subjects who do not differ greatly in terms of the drugs which they had abused or the extent of their abuse. For example, the fact that a neophyte user of narcotics, who has never progressed beyond smoking heroin on an occasional basis, has never been exposed to treatment is by no means comparable with the fact that a person, who has been a daily intravenous user of narcotics, has never been exposed to treatment. This study focuses on serious, established opiate users in order to minimise the possibility that differences in treatment experience might be explained by differences in seriousness of drug habit.

The analysis of survey data examines the exposure to treatment and the abstinence status on reception into prison of the 24 subjects with experience of severe opiate addiction. Treatment is defined to cover all organised intraventions aimed at curing or ameliorating a drug problem, apart from simple detoxification, that is, detoxification which did not also involve specific addiction counselling. Indeed, almost all the subjects (23 of 24) had experienced the detoxification process either on entry to prison or at the National Drug Treatment Centre. Treatment as defined includes group and individual counselling and psychotherapy of the kind offered by the National Drug Treatment Centre, the Anna Liffey Project, the Rutland Centre and other agencies and individual therapists. It also includes periods spent as a member of the Coolmine Therapeutic Community and membership of a Narcotics Anonymous group. Those subjects classified as having no exposure to treatment, had avoided contact with all of these types of intervention.

\section{Results}

Thirteen of the 24 sometime opiate dependent subjects (54\%) had experience of some form of treatment apart from medically supervised detoxification. Conversely, $46 \%$ of the subjects reported that they had experienced no treatment interventions other than detoxification.

Twelve of the 24 subjects (50\%) were abstinent (totally free of opiates) for a period of at least one month prior to their reception into the prison. Table 1 indicates the various lengths of time for which these 12 subjects had been abstinent.

\section{TABLE 1 - Time abstinent}

\begin{tabular}{ccccc}
\hline $1-3 \mathrm{mts}$ & $-6 \mathrm{mts}$ & $-12 \mathrm{mts}$ & -2 yrs. & $>2$ yrs. \\
3 & 2 & 2 & 3 & 2 \\
\hline \multicolumn{4}{c}{ Average time abstinent $=17.5$ months }
\end{tabular}

Five of the 12 abstinent subjects (42\%) had experience of treatment apart from detoxification, while eight of the 12 non-abstinent subjects $(67 \%)$ had such experience. A chisquared test of the null hypothesis, that there is no relationship between experience of treatment and abstinence status, resulted in a chi-squared statistic of 0.67 (1 d.f.). This result is non-significant and so the null hypothesis cannot be rejected. While this lack of statistical relationship clearly runs counter to normal expectations about the effects of treatment, the results for this sample suggest a possible tendency that the untreated group are in fact more likely to be abstinent than the treated group. Sixty-four per cent of the untreated group (seven out of 11 ), compared with $38 \%$ of the treated group (five out of 13 ), were abstinent.

Table 2 presents the results of t-test comparisons between the treated group and the untreated group and between the abstinent group and the non-abstinent group. Only one comparison is statistically significant and this indicates that the currently abstinent group began using opiates when much older than the non-abstinent group (by almost four years). This issue was also examined using chi-squared to test the relationship between abstinence status and whether or not an individual had begun using opiates as a teenager. Fifteen of the subjects had begun as teenagers, of whom four were now abstinent. However, eight of the nine, who began at 20 years or later, were currently abstinent (chi-squared $=6.4$, d.f. $=1$, $\mathrm{p}<.01$ ). The results also show a possible tendency for both the treated and the abstinent groups to be older, in the former case by an average of almost four years, in the latter by an average 
of almost three years, although in neither case is the statistical comparison significant. The time elapsed since beginning to use opiates was, for the non-abstinent group, 7.7 years, and, for the abstinent, 6.7 years, which was not a significant difference $(\mathrm{t}=0.72$, d.f. $=22$, n.s. $)$.

TABLE 2 - Subgroup means and t-test results

\begin{tabular}{|c|c|c|c|c|c|c|}
\hline & Treated & Untreated & $\begin{array}{c}\mathrm{t} \\
(\mathrm{d} . \mathrm{f}=22)\end{array}$ & Abstinent & $\begin{array}{c}\text { Non- } \\
\text { Abstinent }\end{array}$ & $\begin{array}{c}\mathrm{t} \\
(\mathrm{d} . \mathrm{f}=22)\end{array}$ \\
\hline $\mathrm{N}=$ & 13 & 11 & & 12 & 12 & \\
\hline Age & 26.7 & 22.8 & .76, n.s. & 27.4 & 24.6 & 1.37 , n.s. \\
\hline $\begin{array}{l}\text { Age } \\
\text { starting } \\
\text { opiates } \\
\text { Peak daily }\end{array}$ & 19.1 & 18.4 & .48, n.s. & 20.75 & 16.9 & 3.1 $\mathrm{P}<.01$ \\
\hline intake & .73 (grme) & .75 & .1, n.s. & .75 & .72 & .18 , n.s. \\
\hline
\end{tabular}

\section{Discussion}

Since such a large proportion of the prison population tends to have or to have had a serious drug habit - in the present study $25 \%$ of prisoners surveyed had been daily users of opiates, a survey of prisoners provides a unique opportunity for studying the extent of exposure to treatment among the substantial sub-group of the opiate dependent population, who are occasionally prisoners. It is remarkable that almost half of the 24 addicts surveyed had avoided all forms of treatment apart from detoxification, despite an average of more than five years of opiate use, including periods of daily use, which was intravenous in 10 of 11 cases. It is possible that some of the untreated addicts had never had the opportunity for treatment, but it is more plausible that they themselves chose not to avail of treatment. The present findings raise the possibility that drug addicts who undergo treatment are not representative of drug addicts generally and in fact differ in important ways from the addicts who avoid treatment. On the other hand, it should be borne in mind that addicts who end up in prison may differ from those who do not, by being more inclined to avoid treatment.

While the present results indicate that treatment facilities in Ireland are reaching only a proportion of their target clientele, it is perhaps an even more remarkable finding that almost half of the present sample of serious opiate abusers had before their present imprisonment been abstinent for an average of 17.5 months. This is an optimistic finding which counters the defeatist myth of irreversible, ever-deepening and enslaving addiction. However, not only was the general level of abstinence in the sample high, but the level of apparently self-propelled abstinence was also surprisingly high. Indeed, the group who had never experienced treatment, other than detoxification, were the more likely to be abstinent. This suggests that there is a high level of remission without formal treatment amongst the opiate dependent population and, furthermore, it raises the possibility either that present treatment modalities in some way hinder the attainment of abstinence or that it is the addicts, who are least likely to attain abstinence, that are attracted to or encouraged and accepted into treatment programmes.

There is no evidence, from the statistical comparisons undertaken, that the abstinent group had a less serious habit than the non-abstinent group. Both groups had used an almost identical amount of opiates on a daily basis and had been users for many years. It is, therefore, highly improbable that differences in type and seriousness of drug habit explain the differences in abstinence status. However, the currently abstinent group began their opiate use at a significantly older age than the currently non-abstinent. This is an intriguing finding that calls for further investigation, suggesting as it does that early dependence on opiates carries a particularly bad prognosis and is associated with a reduced likelihood of remission, whether following treatment or not.

While considerable caution is warranted in extrapolating from the present results, which are based on a prison sample of small size, the present investigation has served to highlight the vital importance of questions relating to the natural history of opiate dependence to the evaluation of addiction treatment programmes. Clearly, much further investigation is 
required in order to clarify the actual benefits of treatment programmes and to establish whether or not treatment programmes deal with addicts who are significantly different from the addicts who avoid treatment. The present results also suggest that research should focus on the so-called spontaneous remission in order to identify and describe the personal and situational factors which act to promote or inhibit self-controlled abstinence from drugs. Information about these factors might offer invaluable guidance for the treatment of those addicts who do not have the resources to become abstinent without outside support.

\section{References}

1. Marlatt GA, Bauer JS 1988. Addictive Behaviours: Etiology and Treatment Annu Rev Psychol 1988; 39: 223-52.

2. Gossop M. Addiction and after. Br J Psychiatry 1988; 152: 307-9.

3. Nathan PE, Skinstead A. Outcomes of treatment for alcohol problems. J Consult Clin Psychol 1987; 55: 332-40.

4. Gossop M, Green L, Phillips G, Bradley B. 1989 Lapse, relapse and survival among opiate addicts after treatment. Br J Psychiatry 1989; 154: 348-53.

5. Helzer J, Robins L, Taylor J, Carey K, Miller R. The extent of long-term moderate drinking among alcoholics discharged from medical and psychiatric facilities. N Engl J Med 1985; 312: 1678-82.

6. Fillmore KM. Prevalence, incidence and chronicity of drinking patterns and problems among men as a function of age. British Journal of Addictions 1987; 82: 77-83.

7. Nordstrom G, Berglund M. A prospective study of successful long-term adjustment in alcohol dependence. Quarterly Journal for Studies on Alcohol 1987; 48: 95-103.

8. Polich J, Armor D, Braiker H. The course of alcoholism: four years after treatment. New York: Wiley, 1981.

9. Vaillant G. The natural history of alcoholism. Cambridge MA: Harvard University Press, 1983.

10. Gossop M, Green L, Phillips G, Bradley B. What happens to opiate addicts immediately after treatment Br Med J 1987; 294: 1377-1380.

11. Emrick CD. A review of psychologically oriented treatments for alcoholism: 1. Quarterly Journal for Studies on Alcohol 1974; 35: 534-49.

12. Orford J. Excessive appetites: a psychological view of addictions. Chichester: Wiley, 1985.

13. Edwards G, Orford J, Egbert S, Buthrie S, et al. Alcoholism: a controlled trial of treatment and advice. Quarterly Journal for Studies on Alcohol 1977; 38: 1004-31.

14. Emrick CD. 1975 A review of psychologically oriented treatments for alcoholism: 2. Quarterly Journal for Studies on Alcohol 1975; 36: 88-108.

15. O'Mahony P, Smith E. Some personality characteristics of imprisoned heroin addicts. Drug Alcohol Depend 1984; 13: 255-265. 